Article

\title{
The Effect of Tensile Hysteresis and Contact Resistance on the Performance of Strain-Resistant Elastic-Conductive Webbing
}

\author{
Tien-Wei Shyr *, Jing-Wen Shie and Yan-Er Jhuang
}

Department of Fiber and Composite Materials, Feng Chia University, 100 Wenhwa Road, Taichung 40724, Taiwan; E-Mails: P9521309@fcu.edu.tw (J.-W.S.); elaine052773@hotmail.com (Y.-E.J.)

* Author to whom correspondence should be addressed; E-Mail: twshyr@fcu.edu.tw; Tel.: +886-2451-7250 ext. 3418; Fax: +886-2451-4625.

Received: 1 December 2010; in revised form: 20 January 2011 / Accepted: 24 January 2011 / Published: 28 January 2011

\begin{abstract}
To use e-textiles as a strain-resistance sensor they need to be both elastic and conductive. Three kinds of elastic-conductive webbings, including flat, tubular, and belt webbings, made of Lycra fiber and carbon coated polyamide fiber, were used in this study. The strain-resistance properties of the webbings were evaluated in stretch-recovery tests and measured within $30 \%$ strain. It was found that tensile hysteresis and contact resistance significantly influence the tensile elasticity and the resistance sensitivity of the webbings. The results showed that the webbing structure definitely contributes to the tensile hysteresis and contact resistance. The smaller the friction is among the yarns in the belt webbing, the smaller the tensile hysteresis loss. However the close proximity of the conductive yarns in flat and tubular webbings results in a lower contact resistance.
\end{abstract}

Keywords: elastic-conductive webbing; textile strain-resistant sensor; tensile hysteresis; contact resistance

\section{Introduction}

Electronic textiles (e-textiles) can be used in the entertainment industry, fashion industry, communications, as well as for sensing, monitoring, and even locating applications [1-6]. The advantages of e-textiles are not only that they are light, flexible, durable, provide ventilation, and are easily formed, but they are also electrically conductive. One particularly interesting application for e-textiles is its use as a strain-resistance sensor. Changing the resistance of a conductor by stretching 
was first reported by Lord Kelvin [7]. However, because of the rigidity of the gauges, the maximum static strain level that can be applied before failure the measurements were limited to low stress measurements only. Fatigue is another problem in dynamic measurement because of the poor repeatability of alloys in stretch-recovery cycles [7].

Elasticity and conductivity are the two main requirements for e-textiles as a strain-resistance sensor. Tao studied a series of large-strain gauges, in which elasticity was obtained by a knitted structure or by Lycra fiber [7-12]. Abdessalem reported that plated plain knitted fabric using Lycra yarn exhibited serious tensile hysteresis [13]. The recovery in knitted fabric is incomplete depending on the proportion of Lycra yarn in the fabric. This partial non-recovery of knitted fabric is due to the hysteresis of spun yarns having a plastic deformation behavior, which is linked to slippage of the cotton fiber and viscoelasticity. Wu studied polypyrrole (PPy)-coated nylon Lycra fabric [14]. He found that the resistance of PPy-coated nylon Lycra fabric decreased when stretched, but that the tensile hysteresis was significant due to changes in the structure. Strain-resistance sensors, with conductive material coated on the textiles, easily form cracks in the conductive layer when being stretched. This results in poor linearity and repeatability of the relationship between resistance and strain [15]. Sensors based on conductive polymer composite composed of thermoplastic elastomer filled with black particles were studied [16,17]. Mattmann developed a strain sensor using a mixture of thermoplastic elastomer (TPE) and carbon black particles [18]. It proved to have a linear resistance response to strain, but with a small electrical hysteresis, with a maximum hysteresis error $\pm 3.5 \%$ (7\%) in the strain response.

The use of carbon coated yarns wrapped with elastic yarn as a strain sensor was studied by Huang $[19,20]$. It was found that a soft-core yarn sensor can achieve high resistance sensitivity with low linearity. When the sensor consists of high-density piezoresistive fibers, it can achieve high linearity with low resistance sensitivity. The non-linearity of the sensor in the strain-resistance relationship was mainly due to the irregular characteristic of the yarn structure $[19,20]$. Tao observed the change in contact resistance on the textile strain sensor [8]. The contact resistance between two contacting yarns dominates the sensing performance. The contact points of the carbonized single warp knitted fabric influenced the sensitivity, repeatability, hysteresis, linearity, and strain range of the sensor [8]. The hysteresis is caused by friction and structural changes in the fabric. The hysteresis increases with the decrease of fabric density, which determines the number of contact points within a given length of fabric.

$\mathrm{Hu}$ found that a higher level (but close to the percolation threshold) of carbon nanotubes in a polymer composite would increase the resistance sensitivity of that composite [21]. Berger reported that access to a semiconductor region by means of a metal contact usually exhibits a higher resistance than expected from an ideal contact [22]. Komvopoulos reported that although the contact surfaces of microdevices consist of structural polysilicon layers surfaced with gold, the presence of contaminants and insulating films between the contact interfaces may greatly increase the electrical contact resistance [23]. Tersoff reported that if conduction requires either scattering or tunneling, the resistance can easily become much larger [24]. Liu reported that the contact resistance is associated with the conduction characteristic of the contact surface [25]. Slade calculated the electrical contact resistance as the sum of the constriction resistance and the interfacial film resistance [26]. 
However, the structure of a textile, the property of high tensile elasticity with low hysteresis and the property of high electrical resistance sensitivity with low contact resistance in the stretch-recovery cycles are of greater interest as a strain-resistance sensor. In this paper, we designed three kinds of webbings, including flat, tubular, and belt ones, made with Lycra fiber and carbon coated polyamide fiber, which were used as strain sensors. The strain-resistance properties in the stretch-recovery measurement of elastic-conductive webbings were investigated. The effect of the webbing structures on the tensile hysteresis and the electrical contact resistance is analyzed and observed experimentally. The electrical resistance sensitivity of each of these webbings was measured as well.

\section{Experimental Section}

In this study three kinds of webbing structures including flat, tubular, and belt webbings were constructed using conductive yarns and elastic yarns. Polyamide fiber coated with carbon particles (PAC fiber) was used as the conductive fiber (diameter of $50 \mu \mathrm{m}$ ). Fifteen PAC fibers were twisted with a bulky polyester yarn to form a conductive yarn (diameter of $420 \mu \mathrm{m}, 329 \mathrm{kU} / 10 \mathrm{~cm}$ ). The number of twists per meter of the conductive yarn was 80 . Lycra fiber was cross-wrapped by applying two polyester yarns to form an elastic yarn (diameter of $800 \mu \mathrm{m}$ ).

The schematic webbing structures are shown in Figure 1. Flat and tubular webbings were plaited by conductive yarns in a diagonal pattern over and under two yarns [see Figure 1(a,b)]. The elastic yarns were positioned between the conductive yarns as stuffer yarns in the webbing direction [see Figure 1(c)]. Belt webbing consisted of two separate layers with a plain pattern structure, with the warp yarns and weft yarns being interlaced at right angles [see Figure 1(d)]. The elastic yarns were laid in the warp direction of the belt webbing, while the elastic yarns acted as connecting yarns traveling back and faced the layers to hold them together [see Figure 1(e)]. The weft yarn (diameter of $130 \mu \mathrm{m}$, 3.6 MÙ/10 cm) was made from six PAC fibers twisted with one polyester yarn, and the warp yarn was a conductive yarn. The number of elastic yarns and conductive yarns, the density of the weft yarn, and the feed ratio of the conductive yarns for the three webbings are listed in Table 1. The characters E, C, and $\mathrm{D}$ in the webbing code indicate elastic yarn, conductive yarn, and the density of weft yarn, respectively. In the present paper the feed ratio difference of the conductive yarns among the webbings resulted in the structural stability limitation of the webbings.

Figure 1. Structure of (a) flat webbing, (b) tubular webbing, (c) the laid-in elastic yarns of the flat and tubular webbings, (d) belt webbing, and (e) elastic yarn traveling back and faced the layers.

(a)

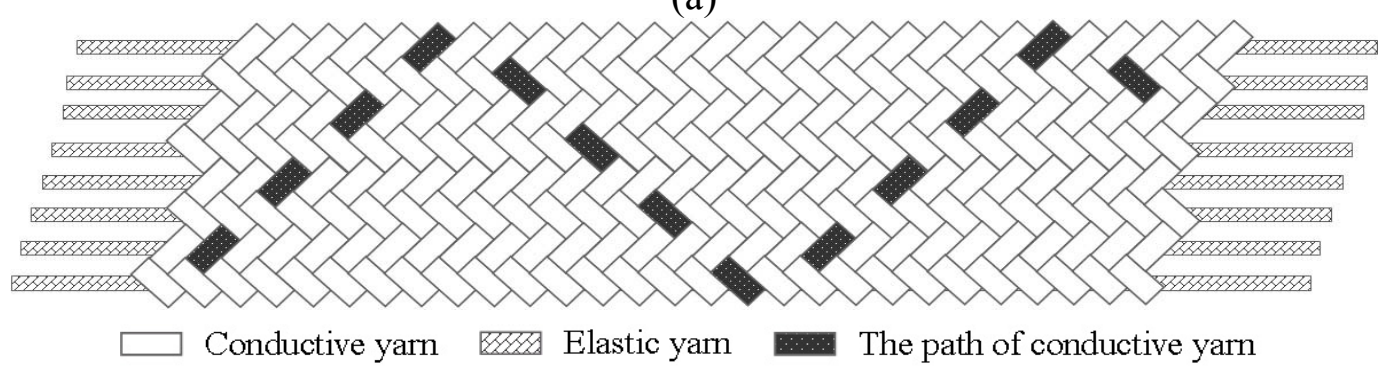


Figure 1. Cont.

(b)

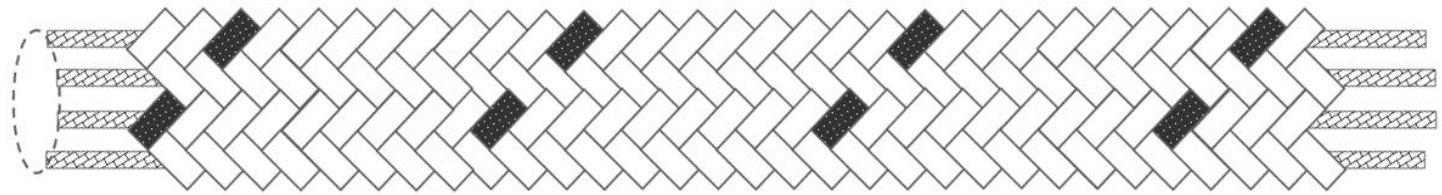

$\square$ Conductive yarn एसz Elastic yarn

The path of conductive yarn

(c)

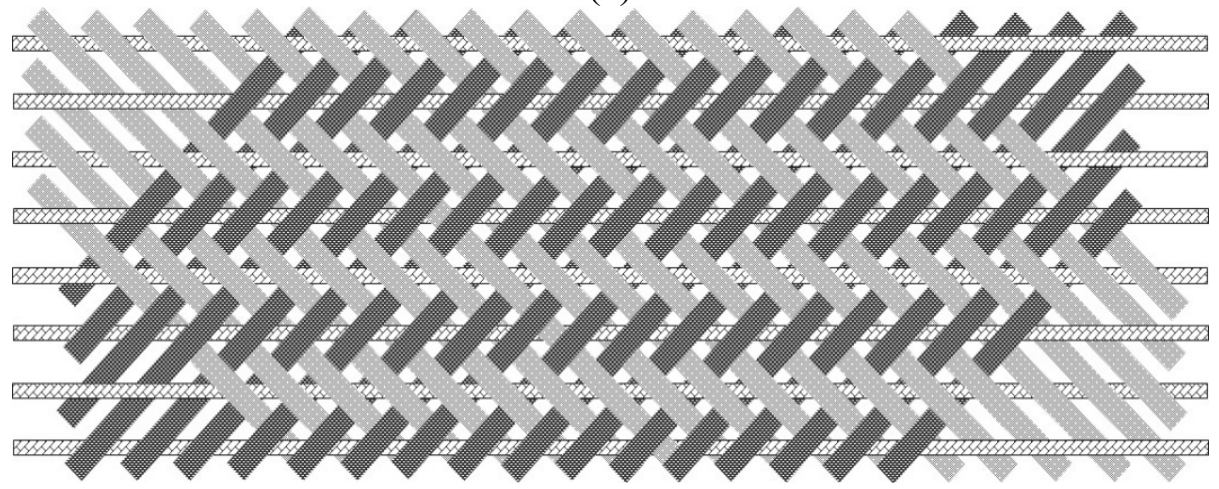

Conductive yarn Elastic yarn

Conductive yarn on the reverse direction

(d)

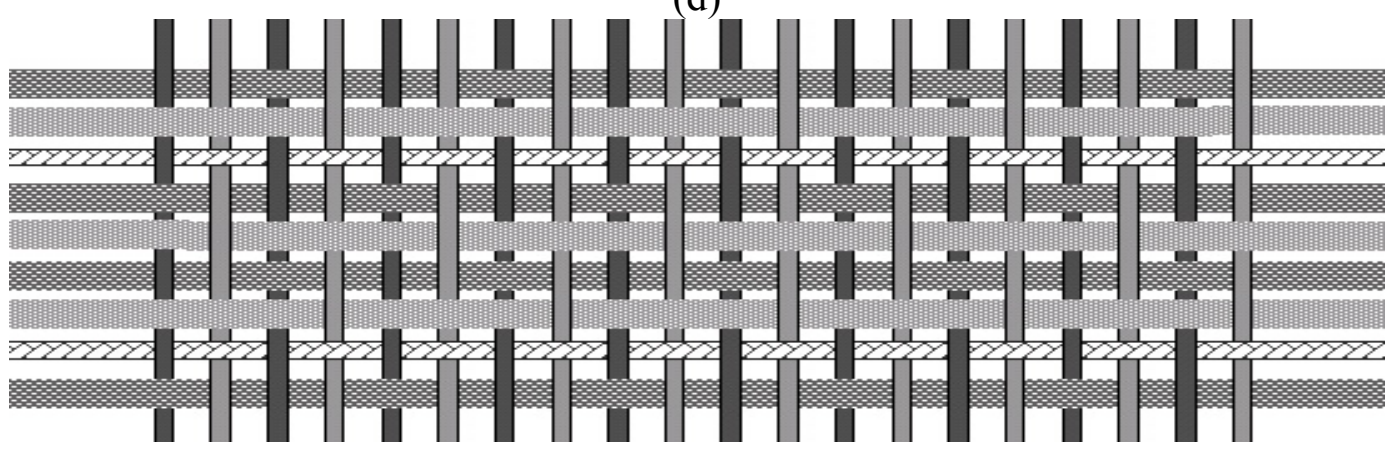

$\longrightarrow$ Weft yarn of the face layer $\quad$ Weft yarn of the back layer

$\square$ Warp yarn of the face layer Warp yarn of the back layer

(e)

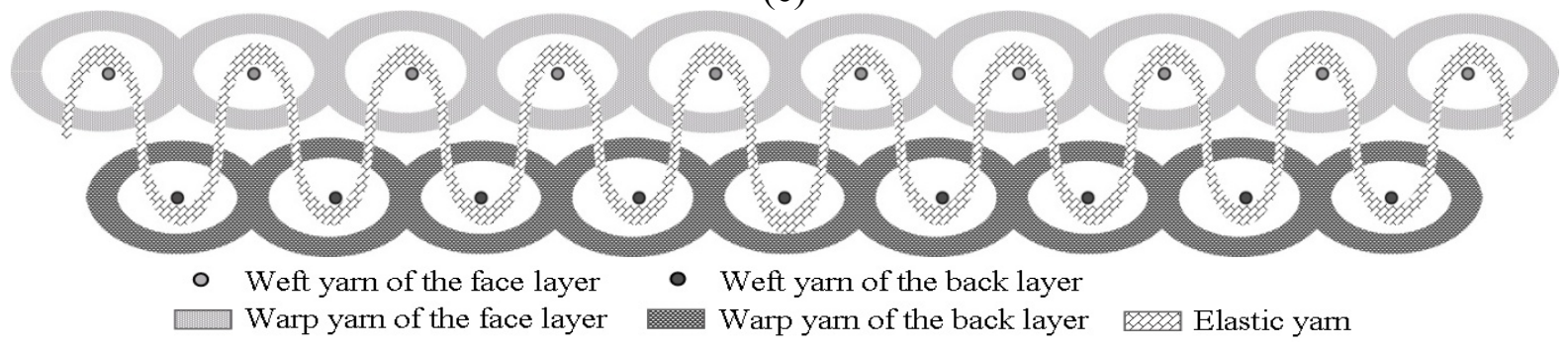


Table 1. The number of elastic yarns and conductive yarns, the density of the weft yarns, and the feed ratio of the conductive yarns of the samples.

\begin{tabular}{cccccc}
\hline Sample Code & Webbing Structure & $\begin{array}{c}\text { Number of } \\
\text { Elastic Yarns }\end{array}$ & $\begin{array}{c}\text { Number of } \\
\text { Conductive Yarns }\end{array}$ & $\begin{array}{c}\text { Density of Weft } \\
\text { Yearns (number/cm) }\end{array}$ & $\begin{array}{c}\text { Feed } \\
\text { Ratio (\%) }\end{array}$ \\
\hline FE08C85 & Flat & 8 & 85 & 370 \\
FE16C85 & Flat & 16 & 85 & 340 \\
TE08C80 & Tubular & 8 & 80 & & 330 \\
TE16C80 & Tubular & 16 & 80 & 4 & 325 \\
BE08C56-D04 & Belt & 8 & 56 & 4 & 310 \\
BE12C88-D04 & Belt & 12 & 88 & 8 & 280 \\
BE12C88-D08 & Belt & 12 & 88 & 12 & 255 \\
BE12C88-D12 & Belt & 12 & 88 & 4 & 185 \\
BE16C120-D04 & Belt & 16 & 120 & 315 \\
\hline
\end{tabular}

Notes: F,T and B in the sample code indicate the flat, tubular and belt webbings, respectively; E08 indicates the eight elastic yarns;

C85 indicates the eight-five conductive yarns;

D04 indicates that the density of the weft yarns is four threads per $\mathrm{cm}$.

The tensile property of the elastic-conductive webbings was measured using a servo control universal testing machine (GT-7001-MC01). The clamping distance was set at $200 \mathrm{~mm}$. Each sample was measured in ten stretch-recovery cycles with 30\% strain. The stretch-recovery speed was a constant $15 \mathrm{~mm} / \mathrm{s}$. The resistance of the elastic-conductive webbings was evaluated for the strain-resistance measurement using a self-assembled apparatus with a milli-Ohm meter (YF-508). The clamping distance was set at $200 \mathrm{~mm}$, and the distance between electrodes was set at $100 \mathrm{~mm}$. A pair of copper electrodes with contact length of $1 \mathrm{~cm}$ was used (see Figure 2). The strain-resistance of the sample was measured by the stretch-recovery tests within $30 \%$ strain. All of the samples had been subjected to a pre-stretch-recovery cycle prior to the measurement. After the measurements the data were fitted by a linear model.

Figure 2. A self-assembled apparatus for measuring the strain-resistance.

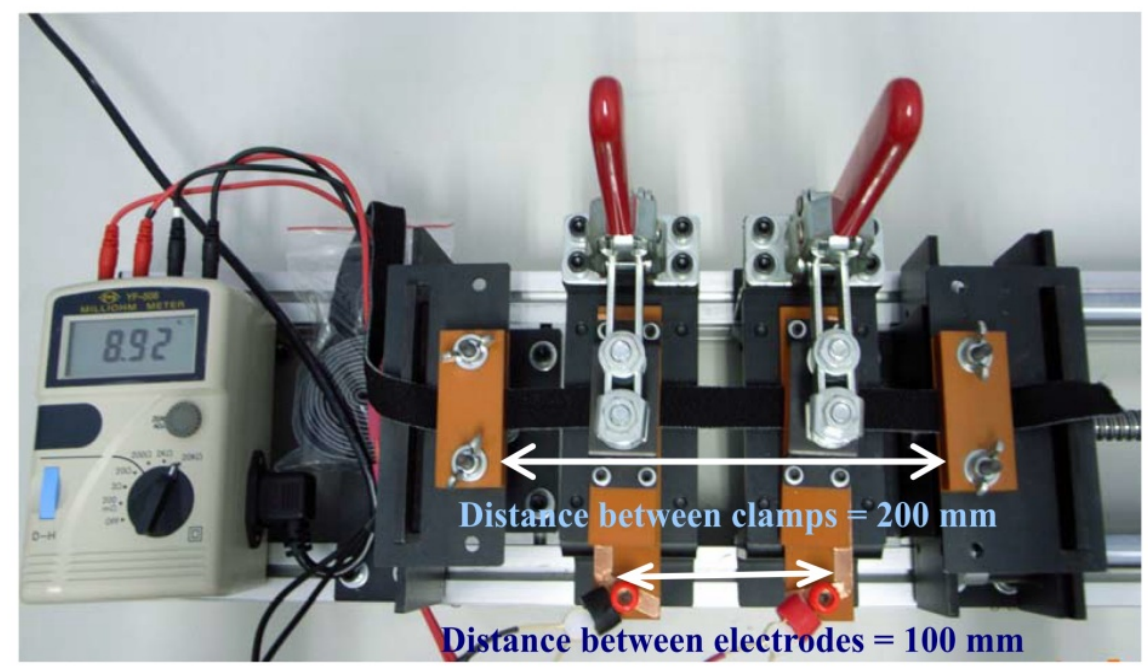




\section{Results and Discussion}

\subsection{Tensile Hysteresis of Webbings}

The typical stretch-recovery cycle of Lycra fibers using a variety of number of strands are shown in Figure 3. The tensile load was proportional to $30 \%$ strain, with coefficients of determination $\left(\mathrm{R}^{2}\right)$ in the range of $0.98 \sim 0.99$, for the stretching and the recovery curves of the samples. Here, the coefficient of determination $\left(\mathrm{R}^{2}\right)$ is such that $0<\mathrm{R}^{2}<1$, and represents the percent of the data that is the closest to the line of best fit [27]. However, in the stretch-recovery measurement the hysteresis phenomenon of the Lycra fiber was obvious. This was due to the friction and structural changes in the molecular chains of the Lycra fiber during stretching and recovery. The hysteresis loss is defined as the area of the hysteresis loop, which is the area between the two curves-stretch and recovery-represents the work loss to the webbing. Although the hysteresis loss increased with the increase in the number of Lycra fibers (see Table 2), the ratio of the hysteresis of the Lycra fibers $\left(\mathrm{H}_{\mathrm{L}}\right)$ to the work, the area under the load-extension curve, at 30\% strain decreased from 11.6\% for eight Lycra fibers (L08) to $9.6 \%$ for sixteen Lycra fibers (L16). The tensile load of elastic yarn showed a good linear relationship to the strain within $30 \%$, with the coefficients of determination $\left(\mathrm{R}^{2}\right)$ being in the range of $0.94 \sim 0.99$, for the stretch and the recovery curves of the samples. However the hysteresis loss of the elastic yarn was greater than that of Lycra fiber (see Table 2). In the present study the hysteresis loss of the samples $(\mathrm{H})$ was defined as the sum of the hysteresis loss of the Lycra fiber themselves $\left(\mathrm{H}_{\mathrm{L}}\right)$ and the friction among the fibers $\left(\mathrm{H}_{\mathrm{F}}\right)$. The ratio of $\mathrm{H}_{\mathrm{F}}$ to $\mathrm{H}$ in the elastic yarns still remains at $15.2 \%$ for the eight elastic yarns (E08). The friction effect between the Lycra fiber and the cross-wrapped polyester yarns is obvious.

Figure 3. Hysteresis loops for 8, 12, and 16 Lycra fibers in the stretch-recovery cycle at $30 \%$ strain.

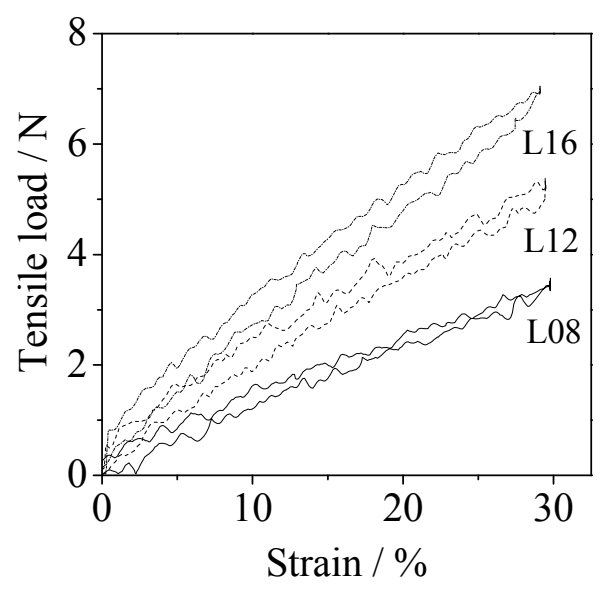


Table 2. Hysteresis loss of webbings during the stretch-recovery measurements at $30 \%$ strain.

\begin{tabular}{|c|c|c|c|c|c|}
\hline \multirow{3}{*}{$\begin{array}{c}\text { Number of } \\
\text { Lycra Fibers }\end{array}$} & \multicolumn{5}{|c|}{ Hysteresis Loss } \\
\hline & \multirow{2}{*}{$\begin{array}{c}\text { Lycra Fibers } \\
(\mathbf{N} \cdot \mathbf{m m})\end{array}$} & \multirow{2}{*}{$\begin{array}{c}\text { Elastic Yarn } \\
(\mathbf{N} \cdot \mathbf{m m})\end{array}$} & \multicolumn{3}{|c|}{ Webbing } \\
\hline & & & Flat $(\mathrm{N} \cdot \mathrm{mm})$ & Tubular $(\mathbf{N} \cdot \mathbf{m m})$ & Belt $(\mathbf{N} \cdot \mathbf{m m})$ \\
\hline 8 & $13.4 \pm 1.2$ & $15.8 \pm 1.5$ & $22.3 \pm 1.6$ & $24.4 \pm 1.3$ & $17.6 \pm 0.7$ \\
\hline \multirow{3}{*}{12} & \multirow{3}{*}{$18.6 \pm 0.4$} & \multirow{3}{*}{$23.5 \pm 0.8$} & & & $\begin{array}{c}28.4 \pm 0.7 \\
(\mathrm{BE} 12 \mathrm{C} 88-\mathrm{D} 04)\end{array}$ \\
\hline & & & & & $\begin{array}{c}31.1 \pm 1.4 \\
(\mathrm{BE} 12 \mathrm{C} 88-\mathrm{D} 08)\end{array}$ \\
\hline & & & & & $\begin{array}{c}55.5 \pm 1.6 \\
(\mathrm{BE} 12 \mathrm{C} 88-\mathrm{D} 12)\end{array}$ \\
\hline 16 & $22.6 \pm 1.1$ & $26.3 \pm 0.9$ & $42.1 \pm 0.7$ & $43.8 \pm 1.0$ & $34.7 \pm 0.7$ \\
\hline
\end{tabular}

Figure 4 shows the typical ten stretch-recovery cycles at $30 \%$ strain of three webbings. All the webbings had good tensile linearity in the stretch and the recovery curves within $30 \%$ strain. The tensile load was proportional to the strain within $30 \%$, with coefficients of determination $\left(\mathrm{R}^{2}\right)$ being in the range of $0.90 \sim 0.99$, for all of the samples. The tensile loads in the different webbings were close to the same at 30\% strain. Based on the tensile performance of the Lycra fibers in Figure 3, it is evident that the tensile load of the webbings mainly contributed on the Lycra fibers.

Figure 4. Typical ten stretch-recovery cycles with 30\% strain of (a) flat, (b) tubular, and (c) belt webbings using sixteen elastic yarns.

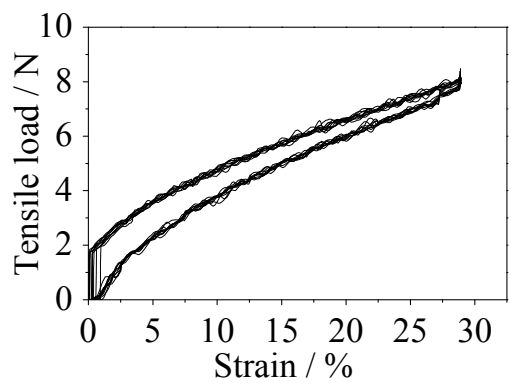

(a) FE16C85

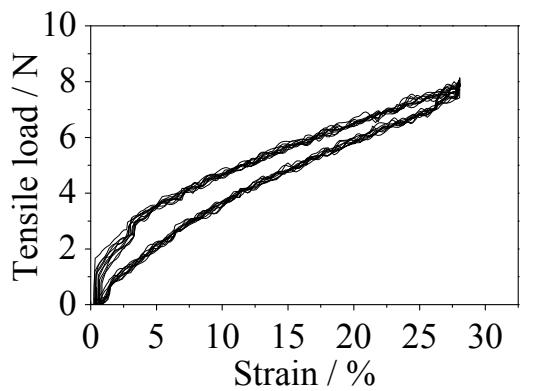

(b) TE16C 80

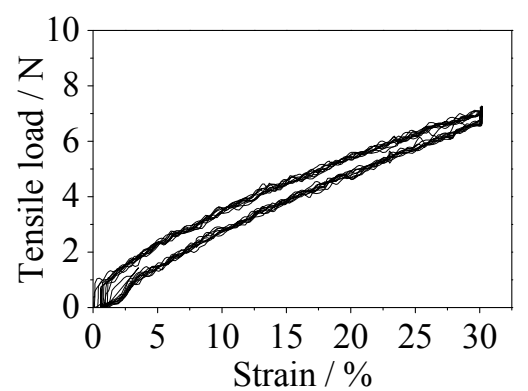

(c) BE16C120-D04

The tensile hysteresis loss of webbings is more than that of the corresponding elastic yarns (see Table 2). The flat and tubular webbings have a similar webbing structure, and are plaited with two conductive yarns in a diagonal pattern with laid-in elastic yarns. The hysteresis losses of flat and tubular webbings show no significant differences (see Table 2). In the belt webbing two separated layers were connected by elastic yarns. The friction among these yarns was less than that in flat or tubular webbings. Thus, the hysteresis loss of flat and tubular webbings is higher than that of belt webbing when they have the same elastic yarns. The tensile hysteresis loss of BE08C56-D04 webbing was $17.6 \pm 0.7 \mathrm{~N} \cdot \mathrm{mm}$ in the stretch-recovery measurement at $30 \%$ strain. The ratio of $\mathrm{H}_{\mathrm{F}}$ to $\mathrm{H}$ in 
BE08C56-D04 webbing approaches $23.9 \%$. When the number of elastic yarns in the belt webbing increased to sixteen, the ratio of $\mathrm{H}_{\mathrm{F}}$ to $\mathrm{H}$ in BE16C120-D04 webbing increased to $34.9 \%$. The ratio of $\mathrm{H}_{\mathrm{F}}$ to $\mathrm{H}$ in flat and tubular webbings shows the same trend. The increase of the number of yarns in the webbing results in an increase in friction among the fibers within the webbings and increases the loss of hysteresis of the webbing. When the weft yarn density of the belt webbings increases the friction between the warp yarns and the weft yarns increases (see Table 2). This results in an increased loss of tensile hysteresis in the belt webbing. The ratio of $\mathrm{H}_{\mathrm{F}}$ to $\mathrm{H}$ in $\mathrm{BE} 12 \mathrm{C} 88$-D12 webbing increased to $66.5 \%$. It is evident that the hysteresis loss of the webbings in the stretch-recovery measurement within $30 \%$ strain is a result of the Lycra fiber itself, the friction among the yarns, and the webbing structures. The number of Lycra fibers, the yarn number, and the webbing structure significantly affect the loss of hysteresis of the webbings in the stretch-recovery measurement.

\subsection{Contact Resistance of Webbings}

The measured resistance of the received PAC fiber, the conductive yarn, and the webbings are shown in Table 3. The results show that the less the number of PAC fibers and the higher the feed ratio of the conductive yarn, the higher the resistance of the webbing will be. The normalized resistance of the PAC fibers $\left(R_{n y}\right)$ in the conductive yarn was calculated as follows: $R_{n y}=R_{m y} \times N_{y}$. Here, $R_{m y}$ is the measured resistance of the conductive yarn per $10 \mathrm{~cm}$ and $\mathrm{N}_{\mathrm{y}}$ is the number of the PAC fibers in the conductive yarn. The normalized resistance of the PAC fibers $\left(\mathrm{R}_{\mathrm{nw}}\right)$ in the webbing was calculated as follows: $\mathrm{R}_{\mathrm{nw}}=\mathrm{R}_{\mathrm{mw}} \times \mathrm{N}_{\mathrm{w}} \div \mathrm{L}_{\mathrm{w}}$. Here, $\mathrm{R}_{\mathrm{mw}}$ is the measured resistance of the webbing per $10 \mathrm{~cm}, \mathrm{~N}_{\mathrm{w}}$ is the number of the PAC fibers in the webbing, and $\mathrm{L}_{\mathrm{w}}$ is the feed ratio of conductive yarn in the webbing (see Table 3). The results show that the normalized resistance of the PAC fiber per $10 \mathrm{~cm}$ increased in the order of the received PAC fiber, followed by conductive yarn, and than the webbings. This is due to the fact that the contact resistance of the samples, which is defined as the ratio of the voltage across the contact to the current flowing through a closed pair of contacts. The contact resistance is associated with the conduction characteristic of the contact surface. The larger the contact area and the less the impurity of the pair materials surface is, the better the conductivity and the lower the resistance [20].

Table 3. Resistance and sensitivity of samples within a 30\% strain.

\begin{tabular}{|c|c|c|c|c|}
\hline Sample Code & $\begin{array}{l}\text { Measured Resistance } \\
(\mathrm{k} \Omega / 10 \mathrm{~cm})\end{array}$ & $\begin{array}{c}\text { Normalized } \\
\text { Resistance of PAC } \\
\text { Fiber }(\mathrm{k} \Omega / 10 \mathrm{~cm}) \\
\end{array}$ & $\begin{array}{c}\text { Measured } \\
\text { Sensitivity of } \\
\text { Webbing }(\Delta \Omega / \%) \\
\end{array}$ & $\begin{array}{c}\text { Normalized } \\
\text { Sensitivity of PAC } \\
\text { Fiber }(\Delta \Omega / \%) \\
\end{array}$ \\
\hline PAC Fiber & $4,077 \pm 255$ & & & \\
\hline Conductive yarn & $329 \pm 3$ & $4,941 \pm 41$ & & \\
\hline FE08C85 & $14.9 \pm 0.2$ & $5,136 \pm 57$ & $103.6 \pm 5.7$ & $35.7 \pm 1.6$ \\
\hline TE08C80 & $14.2 \pm 0.1$ & $5,152 \pm 30$ & $98.9 \pm 1.9$ & $36.0 \pm 0.7$ \\
\hline BE12C88-D04 & $11.7 \pm 0.1$ & $5,526 \pm 30$ & $72.7 \pm 2.8$ & $35.1 \pm 0.5$ \\
\hline BE12C88-D08 & $10.8 \pm 0.1$ & $5,601 \pm 33$ & $74.4 \pm 2.0$ & $38.5 \pm 1.0$ \\
\hline BE12C88-D12 & $8.3 \pm 0.1$ & $5,944 \pm 37$ & $60.0 \pm 1.4$ & $42.8 \pm 1.0$ \\
\hline
\end{tabular}


The fifteen PAC fibers were twisted to form a circular conductive yarn. The current flows across the PAC fibers through a pair of electrodes to measure the resistance of the conductive yarn. The contact resistance was created as a result of the conduction characteristic of the contact surfaces of the PAC fibers and the conductive yarns in the webbing, as well as the conduction characteristic of the contact surfaces between the webbing and the pair of electrodes. The normalized contact resistance of the PAC fiber per $10 \mathrm{~cm}$ of conductive yarn and webbings are given in Table 4 . The contact resistance $\left(\mathrm{R}_{\mathrm{c}}\right)$ was calculated by subtracting the ideal resistance $\left(R_{i}\right)$ from the measured resistance $(R)$. The normalized contact resistance of the PAC fiber $\left(R_{n c y}\right)$ in conductive yarn was calculated as follows: $R_{n c y}=R_{c y} \times N_{y}$. Here, $R_{c y}$ is the contact resistance of conductive yarn per $10 \mathrm{~cm}$. The contact resistance of conductive yarn $\left(R_{c y}\right)$ was calculated as follows: $R_{c y}=R_{m y}-R_{i y}$. Here, $R_{i y}$ is the ideal resistance of the conductive yarn per $10 \mathrm{~cm}$. $\mathrm{R}_{\mathrm{iy}}$ was calculated as follows: $\mathrm{R}_{\mathrm{iy}}=4,077 \div \mathrm{N}_{\mathrm{y}}$. In the study the measured resistance of the received PAC fiber $(4,077 \mathrm{k} \Omega)$ was used as the ideal resistance. The normalized contact resistance of the PAC fiber $\left(R_{n c w}\right)$ in webbing was calculated as follows: $R_{n c w}=R_{c w} \times N_{w} \div L_{w}$. Here, $R_{c w}$ is the contact resistance of webbing per $10 \mathrm{~cm}$. The contact resistance of webbing $\left(R_{c w}\right)$ was calculated as follows: $R_{c w}=R_{m w}-R_{i w}$. Here, $R_{i w}$ is the ideal resistance of webbing per $10 \mathrm{~cm}$. $R_{i w}$ was calculated as follows: $\mathrm{R}_{\mathrm{iw}}=4,077 \div \mathrm{N}_{\mathrm{w}} \times \mathrm{L}_{\mathrm{w}}$. It is evident that the amount of contact resistance in the conductive yarn is significant. The ratio of contact resistance to measured resistance in the conductive yarn was close to $17.3 \%$.

Table 4. Contact resistance of the conductive yarn and webbings.

\begin{tabular}{ccc}
\hline Sample Code & $\begin{array}{c}\mathbf{R}_{\mathbf{i}}+\mathbf{R}_{\mathbf{c}} \text { of Sample } \\
(\mathbf{k} \boldsymbol{\Omega} / \mathbf{1 0} \mathbf{~ c m})\end{array}$ & $\begin{array}{c}\text { Normalized } \mathbf{R}_{\mathbf{c}} \text { of PAC Fiber } \\
(\mathbf{k} \mathbf{\Omega} / \mathbf{1 0} \mathbf{~ c m})\end{array}$ \\
\hline PAC Fiber & $4,077+0$ & 0 \\
Conductive Yarn & $272+57$ & 855 \\
FE08C85 & $11.8+3.1$ & 1,068 \\
TE08C80 & $11.2+3.0$ & 1,091 \\
BE12C88-D04 & $8.6+3.1$ & 1,461 \\
BE12C88-D08 & $7.9+2.9$ & 1,501 \\
BE12C88-D12 & $5.7+2.6$ & 1,855 \\
\hline
\end{tabular}

When the conductive yarns were plaited in flat and tubular webbings or interlaced into belt webbings, the ratio of the contact resistance to the measured resistance of the webbing increased. Compared with the conductive yarns in the flat and tubular webbings, the conductive yarns in the warp of the belt webbing were separated by the weft yarns. The contact resistance in the belt webbing is higher than in the flat and tubular webbings due to the contact characteristic between the conductive yarns and the electrodes. The ratio of contact resistance to measured resistance of the flat, tubular, and belt (BE12C88-D04) webbings are 20.8\%,21.1\%, and 26.5\%, respectively. The normalized contact resistance of the PAC fibers per $10 \mathrm{~cm}$ increased in the order of conductive yarn, followed by tubular and flat webbings, and then the belt webbing (see Table 4).

When the weft yarn density increased in the belt webbing, the contact characteristic between the warp yarns and the electrode were different. The higher the weft yarn density, the more it obstructs the contact between the warp conductive yarns and the electrodes. The contact resistance of the belt 
webbings increased in the order of BE12C88-D04, BE12C88-D08, and then BE12C88-D12. Here the ratio of the contact resistance to the measured resistance of the BE12C88-D12 webbing reaches 31.1\%. The effect of the weft yarn on the contact resistance is significant. The more weft yarn there is in the belt webbing, the more contact resistance there is in the belt. The contact resistance of webbings is not only influenced by the number of conductive yarns, but also by the webbing structure and the weft yarn density.

Due to the presence of contact resistance in the samples, the normalized resistance of the PAC fibers per $10 \mathrm{~cm}$ decreases in the order of belt webbing, flat and tubular webbings, conductive yarn, and the received PAC fiber (see Table 3). The present study shows no significant difference in the normalized resistance of the PAC fibers per $10 \mathrm{~cm}$ between flat and tubular webbings. In belt webbings, the normalized resistance of PAC fiber per $10 \mathrm{~cm}$ increases with the increase of weft yarn density. The better the contact between the conductive yarns in the warp and the electrodes, the lower the contact resistance in the webbing. The measured resistance of the webbing is not only affected by the number and the feed ratio of the conductive yarns, but also by the contact resistance of the webbing.

\subsection{Resistance Sensitivity of Webbings}

Typical strain-resistance curves of webbings in the stretch-recovery cycles are shown in Figure 5. Each curve was plotted using the average of nine measurements. The results show the linear resistance response to the strain in the stretch-recovery measurement within $30 \%$ strain for all the webbings, in which the coefficients of determination $\left(\mathrm{R}^{2}\right)$ of the linear regression curves was 0.99 . The electrical resistance $(R)$ of the materials is equal to $R=\rho \frac{L}{A}$. Here, $\rho$ is resistivity, $L$ is measured length, and $A$ is cross section of the sample. In this work, when the webbing was stretched, the conductive yarns which were overfed in the relaxed state in the webbing were extended. The resistivity $(\rho)$ and the cross section $(A)$ of the conductive fiber in the webbing are not changed. The resistance change of the webbing depended on the extended length of the conductive fiber in the webbing. If the strain in the webbing does not surpass the feed ratio of the conductive fiber in the webbing, the linear resistance responding to the strain in the stretch-recovery measurement can be obtained. No electrical hysteresis was found in this work. The resistance sensitivity of the webbings in the stretch-recovery measurements within $30 \%$ strain was calculated. In this study the resistance sensitivity of the webbings is defined as the resistance change of the webbing under strain (\%). The results are shown in Table 3. The resistance sensitivity of the webbings was affected by the number and the feed ratio of the conductive yarns, and the contact resistance of the webbings. The measured sensitivity of webbing $\left(\mathrm{S}_{\mathrm{mw}}\right)$ was calculated as follows: $\mathrm{S}_{\mathrm{mw}}=\Delta \Omega_{\mathrm{w}} \div 30 \%$. Here, $\Delta \Omega_{\mathrm{w}}$ is the resistance change of webbing under strain $(30 \%)$. The normalized sensitivity of webbing $\left(\mathrm{S}_{\mathrm{nw}}\right)$ was calculated as follows: $\mathrm{S}_{\mathrm{nw}}=\Delta \Omega_{\mathrm{w}} \div 30 \% \times \mathrm{N}_{\mathrm{w}} \div \mathrm{L}_{\mathrm{w}}$. After normalizing the number of PAC fibers and the feed ratio of conductive yarn in the webbings, the normalized resistance sensitivity of the PAC fibers per $10 \mathrm{~cm}$ of FE08C85, TE08C80, and BE08C88-D04 were nearly the same. The differences in contact resistance with varied weft yarn densities in the belt webbings were found. The normalized resistance sensitivity of the PAC fibers per $10 \mathrm{~cm}$ of belt webbing increased in the order of BE12C88-D04, BE12C88-D08, and then BE12C88-D12. The more the weft yarn in the belt webbing, the higher the normalized 
resistance sensitivity of the PAC fiber. The influence of the number and the feed ratio of the conductive yarns and the contact resistance of the webbings on the resistance sensitivity of the webbings are obvious.

Figure 5. Relationship between the resistance and the strain in the stretch-recovery curves (a) varied webbing structures and (b) weft yarn density in the belt webbings.

(a)

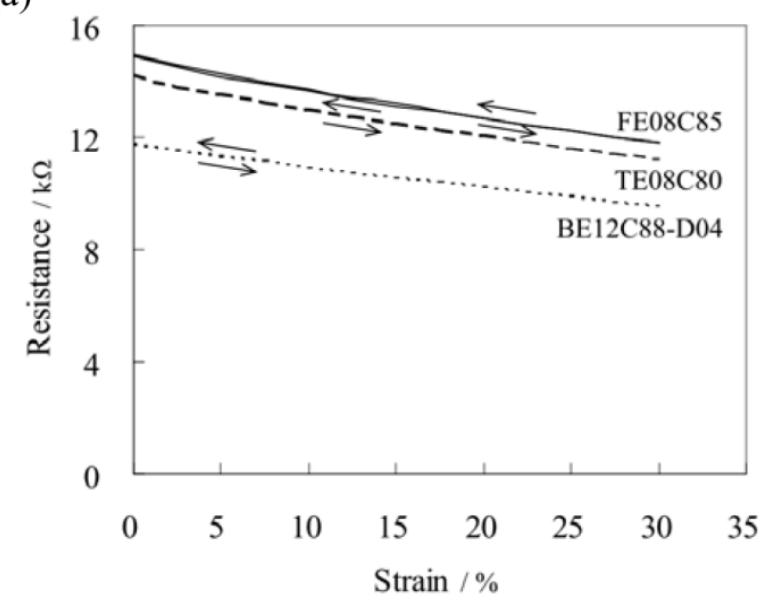

(b)

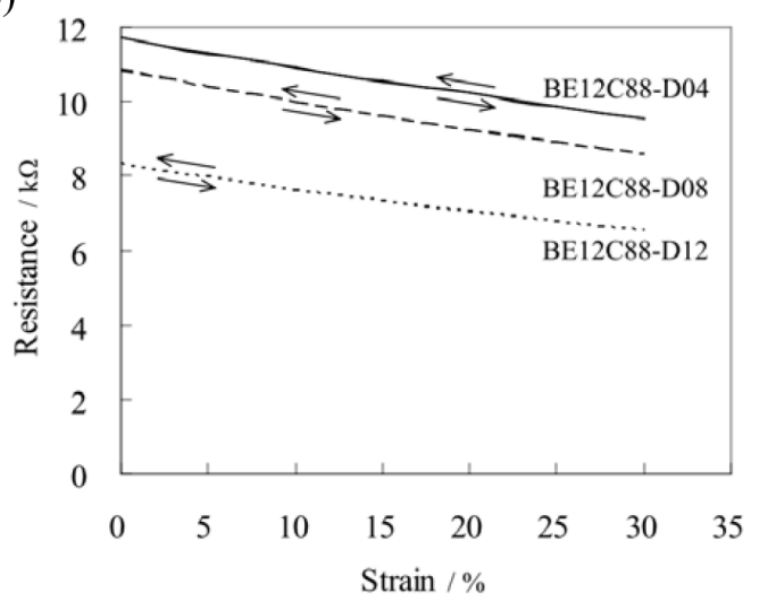

\section{Conclusions}

The strain-resistance in the stretch-recovery measurement of elastic-conductive webbings including flat, tubular, and belt webbings made by Lycra fibers and carbon coated polyamide fibers were investigated. The results showed that all the webbings had a good linear elasticity relationship between tensile load and strain when stretched, and when the recovery curves were within $30 \%$ strain. However, our findings show that there is tensile hysteresis in the webbings during the stretch-recovery measurement. When used as a textile strain sensor, this tensile hysteresis in the stretch-recovery cycle is detrimental to the durability of the strain sensor. The loss of tensile hysteresis of the webbing is due to the hysteresis of the Lycra fibers themselves, the friction among the yarns, and the webbing structure including the yarn density of the belt webbing in the weft. The decrease of friction among the yarns in the webbings decreases the loss of tensile hysteresis. It was found that compared with flat and tubular webbings, belt webbing constructed by two separate layers shows less loss of tensile hysteresis.

The strain-resistance curves of the webbings in the stretch-recovery measurements show that all the webbings show a good linear relationship between resistance and strain. No electrical hysteresis was found in any of the webbings. The resistance sensitivity of the webbing is affected by the conductivity of the PAC fibers, the number and the feed ratio of the conductive yarns, and the contact resistance of the webbing. The contact resistance of the webbing is not only influenced by the number of the conductive yarn, but also by the webbing structure and the weft yarn density in belt webbing. The results show that flat and tubular webbings have a lower ratio of contact resistance to measured resistance.

The stability of elasticity and the resistance sensitivity are two important properties for e-textiles when used as a strain-resistance sensor. In this study, it was found that the tensile hysteresis and the contact resistance influence the elasticity and the resistance sensitivity of the elastic-conductive webbings, respectively. The lower friction among the conductive yarns in the webbing contributes to 
the lower loss of tensile hysteresis. The closer the conductive yarns in the webbing, the lower the contact resistance. The balance between the loss of tensile hysteresis and contact resistance should be considered in the structural design of webbing as a strain-resistance sensor. The tensile hysteresis and the electrical conductivity of the webbings are affected by the measurements as well. They will be investigated in our further study to refine the performance of the textile strain sensor.

\section{Acknowledgements}

This work is supported by the National Science Council of Taiwan, R.O.C., grant number NSC 992218-E-007-001- and by the Ministry of Economic Affairs of Taiwan, R.O.C., grant number 98-EC17-A-19-S2-0133.

\section{References}

1. Carpi, F.; De Rossi, D. Electroactive Polymer-Based Devices for e-Textiles in Biomedicine. Inf. Technol. Biomed. 2005, 9, 295-318.

2. Cochrane, C.; Koncar, V.; Lewandowski, M.; Dufour, C. Design and Development of a Flexible Strain Sensor for Textile Structures Based on a Conductive Polymer Composite. Sensors 2007, 7, 473-492.

3. Post, E.R.; Orth, M.; Russo, P.R.; Gershenfeld, N. E-broidery: Design and Fabrication of Textile-Based Computing. IBM Syst. J. 2000, 39, 840-860.

4. Campbell, T.E.; Munro, B.J.; Wallace, G.G.; Steele, J.R. Can Fabric Sensors Monitor Breast Motion. J. Biomech. 2007, 40, 3056-3059.

5. Martinez, F.; Obieta, G.; Uribe, I.; Sikora, T.; Ochoteco, E. Polymer-Based Self-Standing Flexible Strain Sensor. J. Sensors 2010, doi:10.1155/2010/659571.

6. Cochrane, C.; Lewandowski, M.; Koncar, V. A Flexible Strain Sensor Based on a Conductive Polymer Composite for in situ Measurement of Parachute Canopy Deformation. Sensors 2010, 10, 8291-8303.

7. Zhang, H.; Tao, X.M.; Yu, T.X.; Wang, S.Y. Conductive Knitted Fabric as Large-Strain Gauge under High Temperature. Sens. Actuat. A Phys. 2006, 126, 129-140.

8. Zhang, H.; Tao, X.M.; Yu, T.X.; Wang, S.Y.; Cheng, X.Y. A Novel Sensate 'String' for Large-Strain Measurement at High Temperature. Meas. Sci. Technol. 2006, 17, 450-458.

9. Xue, P.; Tao, X.M.; Tsang, H.Y. In Situ SEM Studies on Strain Sensing Mechanisms of PPy-Coated Electrically Conducting Fabrics. Appl. Surf. Sci. 2007, 253, 3387-3392.

10. Tsang, J.; Leung, S.; Tao, X.M.; Yuen, M.C.-W.; Xue, P. Effect of Fabrication Temperature on Strain-Sensing Capacity of Polypyrrole-Coated Conductive Fabrics. Polym. Int. 2007, 56, 827-833.

11. Li, Y.; Cheng, X.Y.; Leung, M.Y.; Tsang, J.; Tao, X.M.; Yuen, M.C.W. A Flexible Strain Sensor from Polypyrrole-Coated Fabrics. Synth. Met. 2005, 155, 89-94.

12. Li, Y.; Leung, M.Y.; Tao, X.M.; Cheng, X.Y.; Tsang, J.; Yuen, M.C.W. Polypyrrole-Coated Conductive Fabrics as a Candidate for Strain Sensors. J. Mater. Sci. 2005, 40, 4093-4095.

13. Abdessalem, S.B.; Abdelkader, Y.B.; Mokhtar, S.; Elmarzougui, S. Influence of Elastane Consumption on Plated Plain Knitted Fabric Characteristics. J. Eng. Fiber Fabr. 2009, 4, 30-34. 
14. Wu, J.; Zhou, D.; Too, C.O.; Wallace, G.G. Conducting Polymer Coated Lycra. Synth. Met. 2005, 155, 698-701.

15. Calvert, P.; Duggal, D.; Patra, P.; Agrawal, A.; Sawhney, A. Conducting Polymer and Conducting Composite Strain Sensors on Textiles. Mol. Cryst. Liq. Cryst. 2008, 484, 291/[657]-302/[668].

16. Castro, M.; Kumar, B.; Lu, J.; Feller, J.F. Polycarbonate-Carbon Nanotubes Transducers with Hierarchical Structure for Vapor Sensing. In Proceedings of International SAMPE Symposium and Exhibition, Seattle, WA, USA, 17-20 May 2010.

17. Ferro, M.; Pioggia, G.; Tognetti, A.; Carbonaro, N.; Rossi, D.D. A Sensing Seat for Human Authentication. IEEE Trans. Inf. Forensic Secur. 2009, 4, 451-459.

18. Mattmann, C.; Clemens, F.; Tröster, G. Sensor for Measuring Strain in Textile. Sensors 2008, 8, 3719-3732.

19. Huang, C.T.; Tang, C.F.; Lee, M.C.; Chang, S.H. Parametric Design of Yarn-Based Piezoresistive Sensors for Smart Textiles. Sens. Actuat. A Phys. 2008, 148, 10-15.

20. Huang, C.T.; Shen, C.L.; Tang, C.F.; Chang, S.H. A Wearable Yarn-Based Piezo-Resistive Sensor. Sens. Actuat. A Phys. 2008, 141, 396-403.

21. Hu, N.; Karube, Y.; Arai, M.; Watanabe, T.; Yan, C.; Li, Y.; Liu, Y.; Fukunaga, H. Investigation on Sensitivity of a Polymer/Carbon Nanotube Composite Strain Sensor. Carbon 2010, 48, 680-687.

22. Berge, H.H. Contact Resistance and Contact Resistivity. J. Electrochem. Soc. 1972, 119, 507-514.

23. Kogut, L.; Komvopoulos, K. Electrical Contact Resistance Theory for Conductive Rough Surfaces Separated by a Thin Insulating Film. J. Appl. Phys. 2004, 95, 576-585.

24. Tersoff, J. Contact Resistance of Carbon Nanotubes. Appl. Phys. Lett. 1999, 74, 2122-2124.

25. Liu, M. A New Method for Measuring Contact Resistance. In Proceedings of the XXVIIth URSI General Assembly, Maastricht, The Netherlands, 17-24 August 2002.

26. Slade, P.G. Electrical Contacts: Principles and Applications; Marcel Dekker: New York, NY, USA, 1999.

27. Hair, J.F.; Black, W.C.; Babin, B.J.; Anderson, R.E. Multivariate Data Analysis, 7th ed.; Prentice Hall: Upper Saddle River, NJ, USA, 2010.

(C) 2011 by the authors; licensee MDPI, Basel, Switzerland. This article is an open access article distributed under the terms and conditions of the Creative Commons Attribution license (http://creativecommons.org/licenses/by/3.0/) 